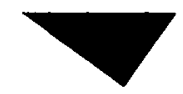

\title{
Terra Estrangeira: "as cores do desterro" da era Collor ${ }^{1}$
}

\author{
Denise Lopes \\ Universidade Federal Fluminense
}

\section{Apresentação}

Terra Estrangeira, realizado $\mathrm{em} 1995$, foi o primeiro filme brasileiro da safra pós-Collor a colocar o dedo diretamente na ferida sobre a condição de estrangeiro em que nos encontrávamos logo após o início do governo Collor, em 1990. Esse "estrangeirismo" de quem não se reconhece mais em seu próprio solo, não faz mais parte, não percebe perspectivas de ser, brechas de se estar, será representado esteticamente no filme de diversas formas, mas, principalmente, através de uma belíssima fotografia em preto e branco de Walter Carvalho, que se insere, literalmente, quase que como mais um personagem, no contexto do filme, preservando elementos ora amplos, ora dissonantes, como forma de expor sentimentos de perda, vazio, delírio e desterro. A narrativa é, em tom poético, também fragmentada. E algumas destas primeiras medidas decretadas por Collor, como o confisco da poupança, anunciado de um aparelho de tevê pela então Ministra Zélia Cardoso de Mello, vão mesmo servir de ponto de partida para o desenrolar da história.

A ponte, apresentada no filme, com Portugal, nosso berço (quer queiram, quer não) de uma nova existência chamada "civilizada", dá a medida exata da busca por um sentido, não mais numa terra idealizada, mas numa terra de despatriados. Uma busca histórica, de alémmar. Como se o filme quisesse nos dizer que, naquele momento, era no estrangeiro que encontrávamos a forma mais razoável de dialogar com a dura realidade que nos era apresentada. Será assim, no exterior, com o olhar de quem está fora, que o filme irá tentar olhar e "oferecer" uma identidade. Uma identidade, que é vendida por 300 doláres, através do passaporte da personagem Alex (Fernanda Torres). Uma 
identidade, que dizem os outros: "não vale nada". Através dessa viagem sem volta, em estradas, cruzando barreiras, de costas para "minhocões" que parecem intermináveis, de frente para navios encaIhados, velhos, que não acharam um cais, mas que ali deram com os cascos, as costas e adernaram, é que vamos nos fitar - para usar um termo mais adequado ao linguajar português/brasileiro/africano do filme, ou à "língua pretoguesa" , como definem seus próprios diretores. Fitar a condição de ser brasileiro, de estar brasileiro, de se estar brasileiro em terras entrangeiras.

Terra Estrangeira já recebeu diversas abordagens eloqüentes de críticos e teóricos do cimena, algumas quase que definitivas, como a do crítico José Carlos Avellar, em publicação sobre o filme da Relume Dumará (1997), ou controversas como a do professor da Escola de Comunicação da UFRJ, André Parente, em "Ensaios sobre o cinema do simulacro" (Pazulin/Rio,98). Mas não há como fugir ao debate. $\mathrm{O}$ presente trabalho visa dar forma ao aprendizado do curso "Produção Audiovisual Fluminense", realizado sob a orientação do professor Roberto Moura, onde conceitos e períodos da trajetória do cinema brasileiro foram estudados sempre diante da ótica política, social e econômica sob os quais se desenvolveram.

Assim, ao tomar o filme de Walter Salles e Daniela Thomas como ponto de discussão estaremos tomando todo um momento pelo qual o país, a nação, e os cidadãos brasileiros estavam passando. A imagem do "minhocão", daquela estrada suspensa, com seus intermináveis carros riscando o chão em alguma direção pode ser entendida aqui como a própria "fuga", "corrida", "direção" que se buscava após as bombardeantes medidas anunciadas pela equipe do presidente Collor. Para a atividade cinematográfica, então, as dúvidas e a falta de caminhos estavam ainda mais latentes após a decretação do fim da Empresa Brasileira de Filmes (Embrafilme) e do Conselho Nacional de Cinema (Concine). Nada disso está dito no filme de Salles e Thomas, mas tudo está. Sugerido por inúmeros processos de cortes/suturas, dissimulado em diversos diálogos, subentendido em vários desmandos dos personagens, o filme _ um grande olhar sobre o momento pelo qual toda uma geração de brasileiros atravessava _, pode ser visto também como metáfora para os próprios caminhos percorridos até ali pelas produções brasileiras, que começavam a ser realizadas, a maioria com personagens estrangeiros ou, simplesmente, falada em outra língua, e filmados, pelo menos em algum momento, fora do país. 
Para discutir esse momento, que Terra Estrangeira retrata, mais do que isso, analisa, o trabalho vai lançar mão, além de uma bibliografia mínima _ há ainda muito poucas publicações sobre esse período recente do cinema brasileiro _, de um levantamento de matérias publicadas entre os jornais da época sobre o fim da Embrafilme. A maioria dos recortes não será citado no desenvolvimento do trabalho, mas de alguma forma dará alicerce à presente pesquisa, situando a época e dando cronologia aos atos que se seguiram à medida provisória que extinguiu a Embrafilme.

\section{Objetivo}

Analisar a estética do filme Terra Estrangeira, de Walter Salles e Daniela Thomas, pelo viéis histórico e econômico do período em que foi realizado e, principalmente, do período que toma como objeto.

\section{Desenvolvimento}

Terra Estrangeira é um filme datado. Sua história se desenrola a partir da posse do presidente Fernando Collor de Mello, no dia 15 de março de 1990, e do anúncio do Plano Collor. O mesmo, que através da medida provisória 151, publicada no Diário Oficial da União, em 16 de março de 1990, extinguiu oito fundações e a Empresa Brasileira de Filmes (Embrafilme). Logo no princípio do filme, uma legenda no canto direito inferior do quadro anuncia: Rio de Janeiro, 13 de março de 1990. Algumas cenas depois: Lisboa, 15 de março de 1990. Essas serão as duas datas grafadas no filme. Daí em diante, não haverá mais a apresentação de datas desta forma, apenas um dia amanhecendo, e já na distante Europa a constatação feita por uma personagem de que se vivia o $1^{\circ}$ de abril, dia da mentira. Vivia-se uma mentira, uma farsa aponta Alex ao lembrar do calendário. As datas inscritas na tela aparecem justamente no início do filme para precisar o momento exato em que o governo Collor começa anunciar suas medidas, entre elas, o Plano Econômico. O desejo de demarcar é tão grande, que Paco (Fernando Alves Pinto) chega a pergunta à mãe (Manuela Laura Cardoso) que horas são. $9 \mathrm{~h} 30$, ela responde e lá fora é noite. Na primeira vez, que a data aparece marcada em números na tela, passa um ônibus. Na segunda, um navio. Sempre meios de transporte, meios de condução, que levam algo de um lugar a outro, meios que passam pela tela, que transportam, que carregam, que podem servir também como meio de fuga, escapismo ou, simplesmente, de viagens de buscas. 
Atônitos ainda pelo pacote de medidas e sem condições de processar e analisar tantas informações novas num curto espaço de tempo, a imprensa só vai começar a publicar matérias analíticas sobre as medidas tomadas na área cultural alguns dias depois. Na edição do dia 21 de março de 1990, o Jornal do Brasil publica, na página 8, do Caderno $\mathrm{B}$, ainda de forma tímida, a primeira matéria tentando discutir o assunto e ouvindo cineastas, assinada pela jornalista Susana Schild, sob o título "Os orfãos da Embrafilme". "Nenhum roteirista de filmecatástrofe poderia prever situação mais calamitosa para o cinema brasileiro", começa a reportagem, que dá conta de pelo menos três cineastas que às vésperas de iniciar filmagens não sabiam mais o que fazer, diante do fim da Embra: João Batista de Andrade, com "Vlado", inspirado na vida do jornalista Vladimir Herzog, Eduardo Coutinho, com "Abolição", e Zelito Vianna, com "Villa-Lobos".

Mas não foram só os cineastas que viram de uma hora para a outra seus projetos caírem por terra. Toda uma geração de jovens passou da perplexidade inicial à mais completa ausência de perspectivas. Muitos foram demitidos de seus empregos e uma grande maioria se viu perdida, sem respostas diante de tantos desmandos. Afinal, eles tinham acabado de eleger o primeiro Presidente da República, através do voto direto, depois de 26 anos de presidentes biônicos. É dessa geração, basicamente, que Terra Estrangeira quer falar. "A imagem do cargueiro emborcado na areia era um emblema do exílio. Não mais o exílio político dos anos de ditadura, mas um novo, econômico, que vem transformando o Brasil dos anos noventa num país da emigração, pela primeira vez em quinhentos anos. Aqui surge a imagem da terra estrangeira como uma solução, também idealizada, para a ausência de perspectiva, de auto-imagem, de identidade"3. E continua, "desejo: o de fazer um filme de geração, sobre jovens desesperançados e sem alternativas em sua própria terra, que são incapazes de se fazer aceitar, de tomar posse de um país, e que portanto se vêem condenados a um estado de eterno deslocamento, o tempo histórico é a virada da década de 80 para 90 _ quando sobraram apenas o discurso político sem ideologia, o escapismo, a alienação e a omnipresença da televisão"4.

Sobre essa "ominipresença da televisão" o crítico Avellar afirma: "A televisão tem algo a ver com tudo isso que se discute em Terra Estrangeira. Não exatamente por uma eventual implicação da televisão nos fatos políticos, mas pela sua efetiva implicação no modo de perceber coisas. Não por uma eventual responsabilidade direta na criação deste lugar ideal para perder-se a si próprio, mas porque se move 
à vontade nele. Por isso, o televisor faz parte da imagem não somente como um objeto de cena mas como um personagem que age, igual a qualquer outro: mata a mãe de Paco em Terra Estrangeira" $(. . .)^{5}$. A televisão vira quase um personagem. Instalada no meio da sala, da cena, narra fatos, apresenta problemas intermitentes na tela/imagem como se fosse o próprio coração da costureira Manuela, mata, como quer o crítico Avellar, e pára de transmitir, de operar, como a Manuela, mãe de Paco, morta no sofá. A tevê vira nessa hora uma extensão daquela mulher. O lugar por onde a vida dela, de toda uma população, passa. Por onde o coração pulsa e apaga.

O trabalho predecessor como documentarista de Walter Salles está presente em Terra Estrangeira camuflado de forma soberba. "Quisemos conscientemente, contar uma estória que partisse de um fato documental recente _o caos resultante do Plano Collor _ para depois desaguar numa ficção, talvez porque tenhamos ficado excessivamente acuados frente à capacidade da televisão de controlar, de definir o passado recente do Brasil _ o que ela faz na verdade de forma tópica, superficial (...) Há algo de fascinante na possibilidade de fazer um filme urgente, que fale de algo que mudou a vida de todo um pais. Esse sentido de urgência determinou a linguagem adotada. Assim, o super $16 \mathrm{~mm}$ não foi utilizado por um questão de custos (embora ajude neste aspecto), mas porque, a câmera mais leve, orgânica a esse tipo de história, aproxima-nos dos personagens".

$\mathrm{Na}$ narrativa acima, fica claro que os desejos estéticos do filme passaram antes de tudo por desejos expressos carregados de sentidos. Nada ali está ao acaso. Nem o super $16 \mathrm{~mm}$, nem o preto/branco _ "o preto e o branco são ao mesmo tempo as cores da esperança e do desespero _ as cores do desterro, tema central do nosso filme" _ nem os enquadramentos, que por vezes parecem querer estourar o quadro no qual se inserem, e muito menos o texto, os diálogos, a narrativa propriamente dita.

Depois de mostrar, pela tevê, Collor e Zélia, somos impactados pela fala arrebatadora, assistida de forma escondida, na penumbra de um palco teatral, na condição semelhante a dos espectadores no cinema, na condição de voyeur. Paco atravessa uma porta onde se lê: proibida a entrada de estranhos. Nós espectadores atravessamos com ele para sermos, como ele, estranho, diferente, estrangeiro na naquele palco (mais uma vez se insere a condição de se estar de fora, de exterioridade, de estranheza, de não pertencer). No palco, a fala é: "Não é monstruoso que este ator aí, por uma fábula, uma paixão 
fingida, possa forçar a alma a sentir o que ele quer, de tal forma que seu rosto empalidece, tem lágrimas nos olhos, angústia no semblante, a voz trêmula e toda a sua aparência se ajusta ao que ele pretende" ${ }^{\text {. }}$. A que teatro se refere este fragmento? A qual personagem podemos embutir esta frase? Quem naquele momento, naquele filme, naquele cenário político nacional parecia mais irreal, mais personagem de si mesmo, mais repleto de angústia, de semblantes que iam mudando e se ajustando ao que se pretendia, quem era mais caricato, mais enlouquecido, mais tomado de algum propósito que nos deixava a sensação de fábula? Aos olhos de todos, de dentro da caixa da televisão, na vida real e no filme, em questão, esse ser não poderia ser tão somente o presidente Fernando Collor, um ator monstruoso de si mesmo. Visto, assim dentro de um filme, dentro da tevê, era ele o ator e não os outros.

Há ainda outras correlações possíveis surpreendentes extraídas do texto de Terra Estrangeira. Quando a personagem Alex (Fernanda Torres) se vira para o amante e diz: "Você gastou toda a sua grana e ainda foi pegar o meu dinheiro para fazer esta porcaria, Miguel" (Alexandre Borges), há uma idéia direta com o fato que acabava de ser narrado: o confisco do dinheiro da poupança de inúmeros brasileiros. Aquela frase poderia muito bem sair da boca de qualquer um dos brasileiros que tiveram seus depósitos bloqueados e que assistiram depois de alguns anos o esquema de corrupção do governo ser desmascarado. O dinheiro, aliás, é algo presente em todo o filme. Costura cenas e é elemento chave. Afinal, a questão econômica é o tema central de Terra Estrangeira. É o confisco, o Plano Collor, a falta de perspectiva, a dificuldade de se ganhar dinheiro que faz os personagem se deslocarem para longe, agirem em negócios escusos, se lançarem no mundo. Há cenas belíssimas envolvendo a questão. A máxima é a das tão cobiçadas pedras preciosas sendo espatifadas pelos sapatos dos transeuntes numa estação de metrô, debaixo do nariz de um cego, que toca violino. A arte se sobrepondo ao lucro, ao dinheiro, à ganância. Esmigalhadas as pedras refletem. Há uma luz "grave", uma luz forte que delas parece emanar. Refletem a fragilidade de suas constituições, a vulnerabilidade de suas existências, a transitoriedade de suas vidas, a insignificância de suas luminosidades diante de algo maior. Refletem exatamente o pouco que são. Refletem a efemeridade da vida. E traduzem a melhor resposta a tudo que Collor impingiu ao pais, aos brasileiros, à cultura (traduzida naquele ato de tocar um violino) e ao cinema nacional. 
Há fragmentos aqui e ali, que lembram ainda o sentimento de torpor, como o outdoor com o Hope (esperança) escrito em letras garrafais, os óculos espatifados do amigo de Alex e Paco, o hotel que se chama Hotel dos Viajantes, e o discurso de Igor (Luis Melo): "puta aventura, a maior aventura de todos os tempos, a dos conquistadores. E você acha que as pessoas querem saber disso? A memória, Paco, foi-se embora junto com o ouro". Há também a música Vapor Barato de Macalé e Waly, cantada por Gal Costa, que vai fazer ainda alusão à relação com o dinheiro: "Oh, sim, eu estou tão cansado, mas não pra dizer que eu não acredito mais em você. Com minhas calças vermeIhas, meu casaco de general, cheio de anéis. Vou descendo por todas as ruas e vou tomar aquele velho navio. Eu não preciso de muito dinheiro, graças a Deus, e não importa honey. Ó minha honey baby, honey baby..." Honey, que se confude com money, talvez, não no sentido de doce mel, mas de amado, de estimado, de caro. Caro, sim, aquele amor e não as pedras. Mas como as pedras, o amor de Alex, Paco, também é vulnerável, foi baleado, perde sangue, sofre e pode morrer. O ser humano também é nada. A vida também passa.

E, por último, há a fotografia, a mais importante como estética no filme. "A fotografia haveria de sair desse mundo em mutação. O roteiro indicava esta atmosfera - um road movie em preto e branco, quase um documentário" , afirma Walter Carvalho. Na tentativa de dar esse efeito, Carvalho constrói uma técnica precisa, que incorpora um pouco da movimentação da câmera do vídeo e que lembra a "câmera na mão" do Cinema Novo. A imagem parece granulada, parece ter, assumir, texturas luminosas, que espelham como as pedras preciosas do chão. A angulação diferenciada de alguns quadros. O quadro quase estourado. As visões de personagem que acompanham movimentos de baixo para cima e os espaços amplos, como na cena em que Alex e Paco passeiam num pátio, onde o que se vê primeiro é uma cruz, uma cruz enorme, dimensionando o tamanho da cruz que os personagens carregavam. A crucificação daqueles que foram despatriados por um desmando econômico.

Para o professor André Parente da UFRJ, no entanto, Terra Estrangeira se insere dentro de um conjunto de filmes que não tem nada a dizer. "Houve um tempo em que nosso cinema era a afirmação de um modo de existência, de uma visão de mundo, de um corpo de sensações (...) não há nada a ser dito, nenhuma realidade a ser inventada, nem mesmo a do cinema, que se torna cada vez mais terra estrangeira" ${ }^{10}$, afirma. "Um dos principais traços da cultura pós-moderna é que 
vivemos no mundo como num sonho: nada parece nos concernir (...) Este traço parece tomar conta da recente produção de filmes brasileiros: não podemos negar que em grande parte, tudo ou quase tudo, nos soa estranho: os personagens, a língua, os atores, os gestos, e muitas vezes a mise-en-scène, que se apresenta como uma revisitação de modelos do passado" "1 , continua. "E como se não bastasse, não filmamos mais aqui como no estrangeiro, filmamos literalmente no estrangeiro: é o caso de (...) Terra Estrangeira, onde somos estrangeiros em fuga em terra estrangeira." 12 Terra Estrangeira não é refém do que Parente aponta. Pelo contrário, lança mão de artifícios como esses exatamente para denciar essa problemática.

André Parente é sensível ao momento da produção brasileira e tem razão no que detecta, em muitos casos acerta em cheio, mas duvido de suas conclusões totalizadoras e por demais abrangentes. Falta, talvez, pressentir que neste modo que ele chama de "revisitativo", carregado de "estrangeirismo", em que nada parece concernir há algo sendo dito. Quem sabe com a mesma força que outras coisas já foram ditas pelo próprio cinema no passado. Falta, como diz Avellar em Para um espectador desatento, largar o "controle remoto". " (...) acostumamos a perceber o país como um programa que passa na televisão para um espectador (desatento, desagregado, perdido de si próprio) com um controle remoto na mão para mudar de canal a todo o instante ("eu tenho pressa e tanta coisa me interessa, mas nada tanto assim"). Um espectador mais ostra e vento que qualquer outro"13. Quando Parente mistura no mesmo caldeirão filmes como Carlota Joaquina, de Carla Carmurati, O Monge e a filha do carrasco, de Walter Lima Jr, e Terra Estrangeira parece ter ligado o "controle remoto" para o qual Avellar chama atenção, parece pecar naquilo que mais contesta: a política de resultados. Terra Estrangeira sintetiza melhor o que se passa com essa geração 90 do cinema brasileiro, que ele chama de "cinema de replicantes", do que os enredos de seus artigos.

"Nada nos é estrangeiro, pois tudo o é", parafraseando Paulo Emílio Gomes, Parente continua, no mesmo artigo, sustentando de que passamos pela "impossibilidade de se viver a história" e pergunta, entendendo o cinema como "espaço_crítico do audiovisual": o que quer o que pode esse cine- ma?

A isso Terra Estrangeira responde: "Isto aqui não é sítio para encontrar ninguém. Isto é uma terra de gente que partiu para o mar. É o 
lugar ideal para perder alguém, ou para perder-se a si próprio". Assim é o cinema, a criação artística. Esse espaço crítico, exercido por Terra Estrangeira, quer só perguntar, deixar dúvidas, fazer com que por duas horas e pouco possamos nos perder ainda mais do que já nos perdemos, possamos ser estrangeiros de nós mesmos para que assim, desligados do nosso próprio "controle remoto", possamos nos perceber de fora. E isso não é pouco não.

Retomando o que Paulo Emílio já dizia no início dos anos 70 "Não somos europeus, nem americanos do norte, mas destituídos de cultura original, nada nos é estrangeiro, pois tudo o é. A penosa construção de nós mesmos se desenvolve na dialética rarefeita entre o não ser e o ser outro"14 _, olhamos para Terra Estrangeira ainda com mais curiosidade, pois, talvez, seja esse o filme nacional que tenha levado mais ao pé da letra essa construção de ser outro ou de não ser _ "Eu não sou ninguém. Você menos ainda e o outro ninguém acabou morrendo três dias atrás"'s , diz Alex.

\section{Conclusão}

"Qualquer filme exprime, ao seu jeito, muito do tempo em que foi realizado"16. A frase de Paulo Emilio Gomes cai como uma luva para o trabalho em questão. Terra Estrangeira, embora ficcional, é quase um documentário de uma época, uma parcela da história. Historiadores daqui a dez, vinte, cem anos poderão tomar suas imagens como o retrato de uma geração, a consequiência de um ato político. Desta forma, estaria o filme inscrito como material para a produção, e por que não, de um saber histórico. Terra Estrangeira não tem a forma de um papiro, se expressa em película, mas mesmo assim é história, a história do pós-Plano Collor, a história daqueles que se viram estrangeiros. Terra Estrangeira teria assim papel fundamental no entendimento da história recente brasileira.

"Nesse final de milênio, quando a atividade cinematográfica chega a seu centenário, assistimos a um amadurecimento de perspectivas fundamentais no encontro da História com o Cinema (...) o cinema depois de inicialmente ser considerado pelos intelectuais como um fenômeno secundário, uma forma superficial de entretenimento de massa manipulado por interesses de mercado, indigno de ser considerado pela História, nem os filmes podendo ser considerados como documentos legítimos para o trabalho historiográfico _, hoje se encontra legitimado como objeto de um campo preciso, assim como uma referência para diversos campos do conhecimento, dos quais recebe uma 
atenção especial como fenômeno, fornecendo até, segundo alguns, elementos para a elaboração de uma contra-História"17. Essa é a pretensão deste trabalho. Extrair da estética do filme em questão elementos que possam definir uma História.

Para alguns, como André Parente, isso não seria possivel. Filmes dessa recente safra da produção nacional estariam inseridos apenas numa questão de mercado, numa questão de conquista de bilheteria. Mas mesmo que só assim, de forma redundante, fosse, não estaria aí também uma pista, um indício do momento político, social e econômico de um país? Em contraponto a isso temos mais duas análises, a de Carlos Alberto Mattos e uma outra reeleitura de Paulo Emílio Gomes.

"Dar as costas ao cinema brasileiro é uma forma de cansaço diante da problemática do ocupado e indica um dos caminhos de reinstalação na ótica do ocupante. A esterilidade do conforto intelectual e artístico que o filme estrangeiro prodiga faz da parcela de público que nos interessa uma aristocracia do nada, uma entidade em suma 68 muito mais subdesenvolvida do que o cinema brasileiro que desertou"18. Terra Estrangeira é cinema brasileiro e do bom, mas deu as costas ao Brasil, deliberadamente, não por questões de mercado, mas porque havia ali um cansaço. Um cansaço traduzido nas pernas cambaleantes da mãe de Paco subindo as escadas. Um cansaço da impossibilidade de se viver aquele momento. Um cansaço de não se poder ser brasileiro, que a faz lavar o rosto, tentar achar outro naquele espeIho. Um cansaço que leva Alex a vender sua única identificação na condição de brasileira no exterior.

Aliado a isso havia a necessidade de "abrir um diálogo com um público que havia se desacostumado a ver o Brasil em tela grande, e para o qual cinema, de alguma forma, era domínio de estrangeiros"19. A "procura de um internacionalismo conceitual mediado pela estetização, como em Terra Estrangeira. O que importa é que esse "estar dentro e fora do país ao mesmo tempo""20. "Terra Estrangeira pode ter sido o grito de independência da linguagem no novo cinema brasileiro."."1

"Ninguém espere ver a desconstrução da linguagem cinematográfica nem a dinamitação do discurso nos moldes dos anos 60 . As experiências mais interessantes se realizam dentro de convenções narrativas firmes, onde a opção pela ousadia não dispensa a comunicação com um espectador medianamente informado, razoavelmente familiariza- 
do com a linguagem audiovisual contemporânea. O que está crescendo neste momento é a consciência de que o cinema não é um mero suporte para histórias contadas de acordo com o figurino clássico. O cinema passa a ser um instrumento com características próprias: a câmera existe para ser movimentada, desequilibrada; a imagem existe para ter sua textura trabalhada, alterada; a ficção se mescla ao documentário para compor narrativas híbridas; o tempo cinematográfico se movimenta para romper a linearidade" 22 , afirma ainda Mattos.

O que para a professora Ivana Bentes criou a seguinte máxima: a de que "o cinema brasileiro contemporâneo seria o negativo do Cinema Novo (glorioso, impopular, desconsertante), um cinema de "mercado", despretensioso, sem ambições estéticas ou políticas, feito para ser consumido e esquecido na "normalidade" da cultura de massas e cujo desejo supremo é ser confundido com o cinema médio americano.".". Seria? Quando Paco. debaixo do chuveiro proclama aos deuses, com a água e a luz inundando sua casa, carregando suas memórias, traduzidas em fotos - algumas delas nunca vistas, como as da replicante (a qual tanto Parente faz menção) de Blade Runner, de Ridley Scott, _não há uma tensão muito similar aos delírios dos personagens glauberianos de Terra em transe ou mesmo de Deus e o diaho na terra do sol. Por que o momento de agora estaria tão distante dessa época, tão menor em valor perante nossos clássicos, vilipendiado e destinado a ser tratado como um subproduto?

E é a própria lvana Bentes que nos daria subsídios a responder a essa pergunta: "A questão está justamente na incompreensão desse passado, tendência de caricaturização e rejeição de toda uma experiência política, estética e de mercado que marcou os anos 60 e 70 "24. Se o passado ainda não foi totalmente entendido, o que falar da incompreensão deste presente? "Precisamos criar condições para a realização de estudos sistemáticos de um corpus largo das cinematografias regionais e nacionais e para a disponibilização para a sociedade."25 Esse corpus largos a que Roberto Moura se refere e pede se assemelha ao desejo de Avellar de que se largue o "controle remoto". Ou seja, é preciso incorporar novas manifestações cinematográficas da nossa história, sem redundâncias e, principalmente, sem medos. Afinal, "a compreensão de que o objeto da História não é o passado mas o próprio tempo, mais especificamente, as transformações dos fenômenos no tempo" "26, nos deixa a obrigação de acompanharmos nosso tempo desarmados de "controles remotos", de não sermos mais um "espectador desatento", como nos fala Avellar. 
"O cinema que temos hoje nasceu de três fatores que se complementam, mas que não determinaram nada por si próprios: 1- a descompressão política da derrocada, primeiro moral, depois legal do governo Collor; 2- o advento de leis de incentivo eficazes, que passaram a ser usadas com razoável profissionalismo; 3- a entrada no meio cinematográfico de realizadores e técnicos advindos de outras áreas menos afetadas pelos anos de crise: teatro, produção musical, vídeo independente, curta-metragem." 27 A tudo isso, podemos somar mais um rosário de fatores. Terra Estrangeira com sua singularidade juntou muitas pedras, diria até que preciosíssimas, a esse quebra cabeça. Resta saber se como os transeuntes daquele metrô não vamos apenas esmagá-las com as botas da nossa displicência cega de sentido, da nossa altivez de julgamento rápido, da nossa desatenção perniciosa. Frutos _ para ainda acabar com o filme _do vício a que estamos acostumados a viver do "império da mediocridade (...), dos engarrafamentos em shoppings, dessa falsa modernidade de janotas incultos, de lejtores de Sidney Sheldon. É o fim do mundo! É o fim do mundo!".

\section{Bibliografia}

AVELLAR, José Carlos. Para um espectador desatento in Cinemais, Revista de Cinema e Outras Questões Audiovisuais, $n^{\circ} 11$, Rio de Janeiro, 1998.

BENTES, Ivana. Do nacional ao transnacional in Cinemais, Revista de Cinema e Outras Questões Audiovisuais, $n^{\circ} 11$, Rio de Janeiro, 1998.

GOMES, Paulo Emílio. Cinema: Trajetória no subdesenvolvimento, Paz e Terra, Rio de Janeiro, 1980.

MATTOS, Carlos Alberto. A Coca-colar e o cocar in Cinemais, Revista de Cinema e Outras Questões Audiovisuais, $n^{\circ} 11$, Rio de Janeiro, 1998.

MATTOS, Carlos Alberto. Sinais de Vida in Cinemais ${ }^{\circ} 11$, Rio de Janeiro, 1998.

MOURA, Roberto. Cinema e História, Cinema brasileiro: atualidades e reminiscências inspiradoras in Cinemais, Revista de Cinema e Outras Questões Audiovisuais, $\mathrm{n}^{\circ} 10$, Rio de Janeiro, 1998.

PARENTE, André. Ensaios sobre o cinema do simulacro, Pazulin Editora, Rio de Janeiro, 1998. 
PARENTE, André. Cinema Brasileiro, Terra estrangeira in Cinemais, Revista de Cinema e Outras Questões Audiovisuais nº 4 , Rio de Janeiro, 1997.

SALLES, Walter, Daniela Thomas e Walter Carvalho, Terra Estrangeira, Relume Dumará, Rio de Janeiro, 1997.

Matérias de jornais da época da extinção da Embrafilme

- Embra dá e não cobra. A estatal finacia 30 filmes por ano e reconhece que poucos cineastas pagam o que devem. O Globo, Segundo Caderno, 12/03/89.

- Cinema, 20 anos de Embrafilme / À beira do colapso, não há clima de festa no cinema brasileiro. Os cineastas dão a Embrafilme como morta e pedem sua reformulação imediata e o fim da burocracia. Mas ainda vão esperar até 1990. Jornal da Tarde, Caderno Artes, 12/09/89.

- Roberto Faria defende privatização da Embra Folha de São Paulo, Ilustrada, 13/03/90.

- Os órfãos da Embrafilme, Jornal do Brasil, Caderno B, 21/03/90.

- Trinta filmes têm estréia cancelada, Folha de São Paulo, Ilustrada, 05/04/90.

- Empresas deixam de pagar Embra sem esperar pela sua liquidaçãa Folha de São Paulo, Ilustrada, 05/04/90.

- O filme depois do fim, Jornal do Brasil, Caderno B, 07/04/90.

- Privatizada, Embra perde maior parte da receita, Folha de São Paulo, Ilustrada, 10/04/90.

_ Embrafilme à venda. Quem vai comprar? Estado de São Paulo, Caderno Dois, 12/04/90.

- Adnor chega à Embrafilme, Jornal do Brasil, Caderno B, 25/04/90.

- Embra tem comprador, Jornal do Brasil, Caderno B, 01/05/90.

- Luis Carlos Barreto quer transformar a Embrafilme numa "trading". O Globo, Segundo Caderno, 06/05/90.

- Rio quer ficar com a Embrafilme. Jornal do Brasil, Caderno B, 16/ $05 / 90$.

- Toma posse hoje o liqüidante da Embrafilme, empresa extinta pelo Plano Collor, Jornal do Brasil, Caderno B, 25/05/90. 
- Embrafilme ainda existe, arrecada verbas mas não investe em cinema. Folha de São Paulo. Caderno Especial: Cultura Collor, 23/ $02 / 91$.

- Rombo na Embra passa de US\$ 5,5 milhões. Folha de São Paulo, Ilustrada, 13/05/92.

\section{Notas}

1 Trabalho apresentado como conclusão do curso Produção Audiovisual Fluminense, ministrado pelo Professor Roberto Moura, no Mestrado em Comunicação, Imagem e Informação da Universidade Federal Fluminense, em 30 de novembro de 1998.

2 SALLES, Walter, Daniela Thomas e Walter Carvalho. Terra Estrangeira, Relume Dumará, Rio de Janeiro, 1997, pág. 13.

3 idem, pg. 13.

4 idem, pg. 14.

725 AVELLAR, José Carlos. Dramaturgias do cinema brasileiro. Para um espectador desatento in Cinemais, $\mathrm{n}^{\circ} 11, \mathrm{pg} .156$.

6 SALLES, Walter, Daniela Thomas e Walter Carvalho. Terra Estrangeira, Relume Dumará, Rio de Janeiro, 1997, pg.14.

7 idem, pg.13.

8 idem, pg. 23.

9 idem, pg. 99.

10 PARENTE, André. Cinema Brasileiro, Terra estrangeira in Cinemais, ${ }^{\circ} 4$, pg. 196.

11 idem, pg. 195.

12 idem, pg. 199.

13 AVELLAR, José Carlos. Para um espectador desatento in Cinemais $n^{\circ} 11$, pg. 159.

14 GOMES, Paulo Emilio. Cinema: trajetória no subdesenvolvimento. Paz e Terra, Rio de Janeiro, 1980, pg. 88.

15 SALLES, Walter, Daniela Thomas e Walter Carvalho. Terra Estrangeira, Relume Dumará, Rio de Janeiro, 1997, pg. 62.

16 GOMES, Paulo Emílio. Cinema: trajetória no subdesenvolvimento. Paz e Terra, Rio de Janeiro, 1980, pg. 98. 
17 MOURA, Roberto. Cinema e História. Cinema Brasileiro: atualidades e reminiscências inspiradoras, Cinemais $\mathrm{n}^{\circ} 10$, Rio de janeiro, 1998, pgs. 172 e 173.

18 GOMES, Paulo Emílio. Cinema: trajetória no subdesenvolvimen10. Paz e Terra, Rio de Janeiro, 1980, pg. 101.

19 MATTOS, Carlos Alberto. A Coca-cola e o cocar in Cinemais $n^{\circ}$ 11 , pg. 40.

20 idem.

21 MATTOS, Calos Alberto. Sinais de Vida in Cinemais $n^{\circ} 11$, pg. 52.

22 idem.

23 BENTES, Ivana. Do nacional ao transnacional in Cinemais $n^{\circ} 11$, pg. 125.

24 idem.

25 MOURA, Roberto. Cinema e História. Cinema Brasileiro: atualidades e reminiscencias inspiradoras in Cinemais n 10, pg. 197.

26 idem, pg. 172.

27 MATTOS, Carlos Alberto. Sinais de Vida in Cinemais $n^{\circ} 11$, pg. 48. 
